\title{
Controlling Noise and Gas Emissions by a New Design of Diesel Particulate Filters
}

\author{
SAYEL M. FAYYAD \\ Department of Mechanical Engineering, Faculty of Engineering Technology, \\ P.O. Box 15008, Al-Balqa Applied University \\ Amman - JORDAN
}

\begin{abstract}
A theoretical and numerical studies on Diesel Particulate Filters (DPF) and its working principal in controlling noise and exhaust gasses emissions is presented here. This research includes a study of current Martials types that is used in diesel particulate nowadays and on a new materials and technologies that we can use in future. A new design of DPF is presented here. Unfortunately, in Jordan we face an environmental problems caused by diesel engines and the production of NOx and other exhaust gases and particulate matter. The main reason of this problem is the low specification of diesel fuel that is used in Jordan, which leads to shorten the life time of the Diesel particulate filters and leading to block them in some intensive cases. This problems leads to increasing the pollutant in the air which can harm the people's health, animal and plants, so this research goal is to find a solution for the diesel particulate filter life time and to control the environmental emissions and engines noise resulted from gas dynamics. It is found that the developed design of DPF achieves about $22 \%$ increase in its performance in both gas emission and noise reductions comparing with the traditional one.
\end{abstract}

. HI: RLGV. -Diesel Particulate Filters, Gas Dynamics, Noise Reduction, Noise Control, Transmission Losses, Pollutions, Emissions, and Automobiles.

Received: January 8, 2020. Revised: May 13, 2020. Accepted: May 26, 2020. Published: June 5, 2020.

\section{Introduction}

The effect of internal combustion engine and diesel motors on the earth and our ways of life has been impressive. In Europe, innovative work take a shot at motors inside the last a few decades has been carefully centred around motor execution regarding power yield, mileage, unwavering quality, and so on., yet not on motor outflows. During late decades, articulated intrigue has concentrated on exhaust discharges and their effect on human beings and nature. Because of the quick increment in the number of vehicles being used, particularly in urban territories, motor discharges have become associated guilty parties for some with the wellbeing impacts saw in urban populaces. A large portion of the enthusiasm for emanations has been centred on traveller autos and other light-obligation vehicles, on the grounds that these classes of vehicles exist in a lot more noteworthy numbers than the rock solid vehicles. Vehicle emanations are typically separated into classes of directed and unregulated contaminations. Controlled contaminations comprise of carbon monoxide (CO), nitrogen oxides (NOx, primarily nitrogen monoxide and nitrogen dioxide), unburned fuel, or mostly oxidized hydrocarbons (HC), and particulates [1]. These poisons are determined by law in the greater part of the modern propelled nations. Unregulated contaminations are characterized as exacerbates that are not indicated by law. These unregulated contaminations may well have a place with the gathering of unburned hydrocarbons, yet not as individual mixes. A few of the mixes present in diesel and fuel motor 
debilitates are known to be cancer-causing or potentially mutagenic. A significant number of the nitrogen oxides are vapid and unscented. In any case, one normal poison, nitrogen dioxide alongside particles noticeable all around can frequently be viewed as a ruddy dark colored layer over numerous urban regions. Residue, is the obvious fumes - the dark smoke you see originating from the stacks. It's comprised of unburned fuel, carbon, and other strong material. Starting January 2007, the Environmental Protection Agency set up new emanation necessities for all diesel motors. These guidelines extraordinarily lessen diesel emanations. As a matter of fact, from 1990 to 2020, the EPA has continuously diminished reasonable NOx levels in diesel fumes an aggregate of 80\%. For 2007 guidelines, the EPA has diminished permissible particulate issue in diesel fumes an aggregate of 90\%. Furthermore, the thing that matters can't what you see on the expressways, but on the other hand it's in a lot of cleaner air and a more advantageous condition. To meet the EPA 2007 levels for particulate issue, all makers went to an Exhaust After-Treatment System. The poor details of the diesel utilized here in Jordan, which is spoken to by the sulphur substance which is, as be talked about, about $15 \%$. Since as the sulphur substance increment the exhibition of the DPF in gasses outflows decrease diminishes quickly. The significant expenses of this innovation It can be reasoned that Jordan can't choose to utilize this innovation except if diesel particular be improved by diminishing sulphur substance or uses some proper added substances ; also this venture must be financed government or other ecological associations One of the productive apparatuses used to lessen the toxins is the diesel particulate channel (DPF). Figure (1) shows awful emanations created by diesel engines [1].

\subsection{Health Effects from}

\section{Automobile Emissions}

Spark-ignition engines are considered as a wellspring of urban air contamination. The motor fumes is the wellspring of nitrogen oxides (NO and NOD and carbon monoxide (CO) outflows. The fumes, the crankcase, the fuel tank and carburettor are the wellsprings of unburned hydrocarbons (HC). Table 1 shows the components of the issue and burning procedure happening in these diverse flash start motors and their effects and toxicity on environment. In this manner, those motor plan and working parameters which influence motor discharges can be distinguished, and the method of reasoning behind current endeavours to control emanations will be obvious.

Black carbon directly affects weather, climate and the environment by absorbing solar radiation or changing the albedo surface and indirectly, affecting the brightness of clouds, emissivity and lifetime, as well as human health. Bond et al. (2013) found that the best estimation of total radiative forcing in the industrial period, taking into account all forcing paths, including interactions with clouds and the cryosphere, is $+1.1 \mathrm{Wm}^{-2}$ with an error range from $0.17 \mathrm{Wm}^{-2}$ to $2.1 \mathrm{WM}^{-2}$. They conclude that, after $\mathrm{CO} 2$, black carbon is the second most important human emission in the modern atmosphere in terms of climate forcing, which affects human health [17, 18]. It is known that emissions from diesel engines and other mobile sources have a serious impact on health. The International Agency for Research on Cancer has added diesel exhaust gas to its list of known carcinogens in 2012. Based on recent occupational exposure studies (International Agency for Research on Cancer 2012- [19]). A comprehensive review of the health effects of traffic-related emissions was published by the Health Effects Institute in 2010; has been proven to cause asthma and 
exacerbation in children, respiratory symptoms in adults, deterioration of lung function as well as mortality and cardiovascular morbidity (HEI 2010). Among the key findings, the study showed that there is a causal relationship between exposure to exacerbation and asthma exacerbation, and that people living 300-500 meters from the highway or main road are in a high exposure zone. The study did not identify one substitute pollutant for traffic-related emissions, potentially increasing the complexity and burden associated with undertaking health impact studies depending on the source [20].

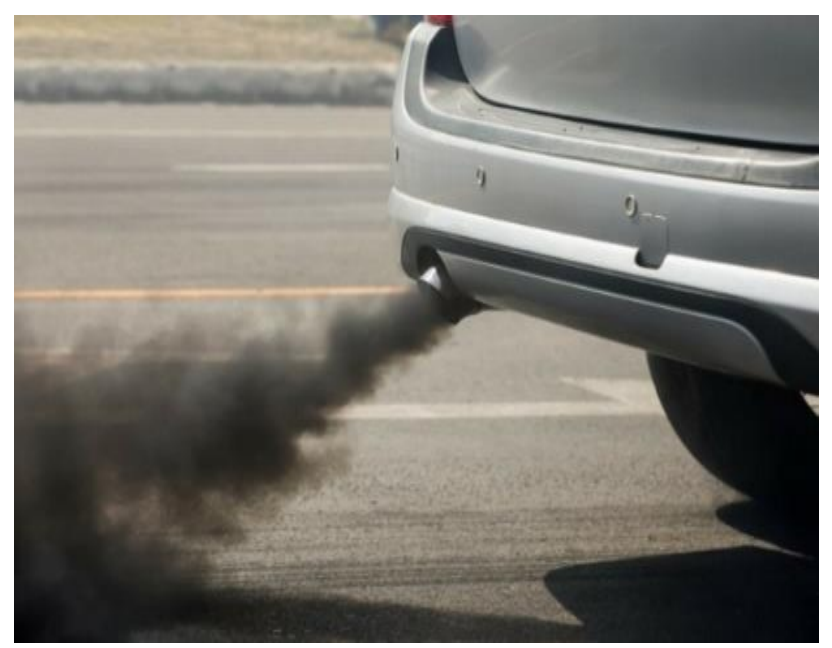

Fig 1: Automobile Emissions

\subsection{Reasons of Diesel}

\section{Particulate Filter (DPF) blocking}

Each vehicle type and engine combination may have different reasons for which the filter block is blocked. The rate of particulate formation by the engine, fuel quality, quality or oil, driving style, and even the location of the particulate filter in the exhaust system can contribute to blockage of the filter or its complete regeneration.

Figure (2) shows a blocked DPF. And the main reasons for blocking DPF are: Use engine oil with a low impurity content: failure to use the right oil for your engine can contribute completely to ash growth in the DPF. $-100 \%$ biofuels for diesel engines: the use of these biofuels can further increase residue accumulation in the DPF, because biofuel may not be consumed as "flawless" (produce more solid particles) like regular diesel fuel.

- City bike ride: not all use our vehicles similarly, without the chance that you will simply use your vehicle in the city, you may encounter faster ash development in the DPF filter, because the recovery procedure may not end in a short city or nearby driving after city. -Temperature: DPF depends on the temperature to recover the channel, around $600 \mathrm{c}$, so many short exits, driving at a low speed will not give the exhaust frame a high enough temperature to start or stop recovery, so the channel may interfere [1].

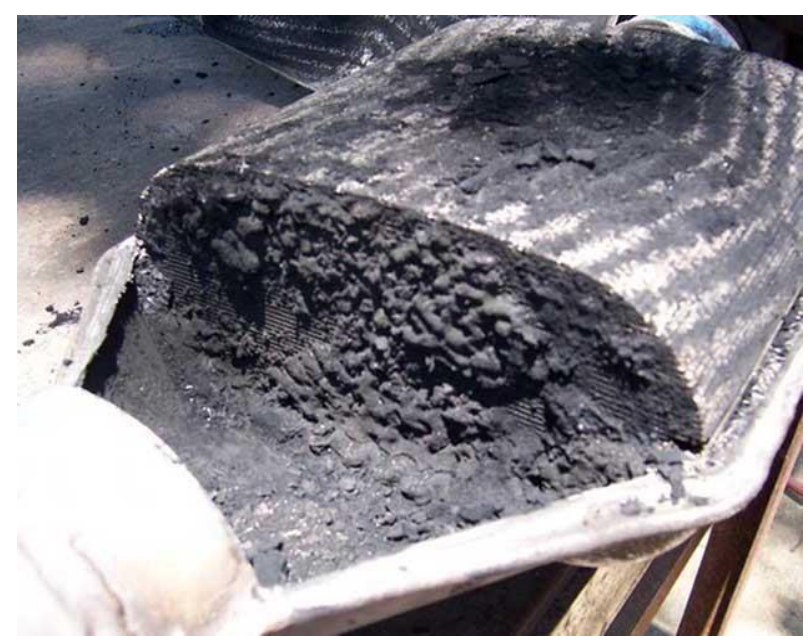

Fig 2: Blocked Diesel Particulate Filter[1]

\subsection{DPF working principle}

The technology in this after treatment system is a diesel particulate filter. DPF replaces the old suppressor and trap. DPF does not consume sediments into the climate, but captures the residues and then uses warm heat to oxidize them. Therefore, the remaining smoke is a lot of clean air. The ash is intermittently recovered into clean carbon dioxide gas and hookah. Subsequent soot was spotless-no smell or diesel smell. The diesel particulate channel can quickly collect a large amount of ash. A few litres of residue are collected every day from hard-core trucks or 
transport motors. Eventually, the accumulated particles will cause excessive smoke pressure drop in the channel, which will adversely affect the motor's activity.

\section{Table 1. Summary of automobile urban air pollution problem [1]}

\begin{tabular}{|c|c|c|c|c|c|}
\hline \multirow{2}{*}{ Pollutant } & \multirow{2}{*}{ Effects } & \multirow{2}{*}{$\begin{array}{l}\text { Emission } \\
\text { source }\end{array}$} & \multicolumn{2}{|c|}{$\begin{array}{c}\text { Automobile emissions } \\
\text { in grams per average } \\
\text { vehicle mile }\end{array}$} & \multirow{2}{*}{$\begin{array}{c}\text { Mobile } \\
\text { source } \\
\text { emissions } \\
\text { as } \\
\text { percentage } \\
\text { of total } \\
\text { emissions* }\end{array}$} \\
\hline & & & $\begin{array}{l}\text { Uncontrolled } \\
\text { vehicle }\end{array}$ & $\begin{array}{l}\text { New } \\
\text { vehic } \\
\text { le }\end{array}$ & \\
\hline $\begin{array}{l}\text { Oxides of } \\
\text { nitrogen } \\
\text { (NO and } \\
\text { NO2) }\end{array}$ & $\begin{array}{l}\text { Reactant in } \\
\text { photochemical } \\
\text { smog NO2 is } \\
\text { toxic }\end{array}$ & Exhaust & 4 & 3 & $60-75$ \\
\hline $\begin{array}{l}\text { Carbon } \\
\text { monoxide } \\
\text { (CO) }\end{array}$ & toxic & Exhaust & 90 & 15 & 90 \\
\hline $\begin{array}{c}\text { Unburned } \\
\text { hydrocarbo } \\
\text { ns (HC, } \\
\text { many } \\
\text { hydrocarbo } \\
\text { n } \\
\text { compounds) }\end{array}$ & $\begin{array}{l}\text { Reactant in } \\
\text { photochemical } \\
\text { smog }\end{array}$ & $\begin{array}{c}\text { Exhaust } \\
\text { Evaporation } \\
\text { Crankcase }\end{array}$ & 3 & $\begin{array}{l}2 \\
0\end{array}$ & $60-80$ \\
\hline
\end{tabular}

* Depends on type of urban area and source mix.

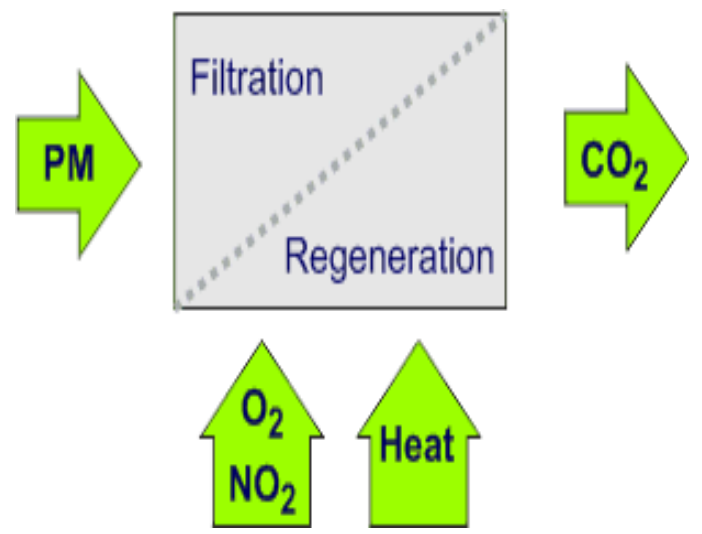

Fig 3: Schematic of particulate filter with thermal regeneration
In this way, the particulate filter skeletons must provide a method for expelling particulate matter from the duct to restore the sludge range. This solids removal, known as channel recovery, can be performed either continuously during normal channel activity, or sporadically, after accumulating a predetermined amount of residue. In both cases, the recovery of the channel backbone should be "invisible" to the driver / vehicle administrator and should be performed without its mediation. As a rule, heat recovery is used in diesel oil channels, where the collected particles are removed from the snare drum by oxidation to steam elements, in principle to carbon dioxide $(\mathrm{CO} 2)$.

To ensure that solid particles are oxidized at the correct rate, the channel must be operated at the appropriate temperature and oxidizing gases, for example oxygen or nitrogen dioxide (or its predecessors) must be supplied to the channel. Reduction of NOx outflow with and without the use of a reagent converter. The decrease in NOx emissions concerned the basic response. The NOx decrease is around. $61 \%$ using a copper oxide exhaust system. Another basic DPF job is to reduce motor noise [1]. The acoustic properties of DPF frames have been the subject of many hypothetical and trial tests, many articles have discussed the role of DPF in reducing engine noise. The traditional DPF is discussed in [1] to [12] and [14] as a device to make gas emission reduction and also its work principle is explained, the effects of its properties is discussed also, the factors affects its role in gas emission reduction is explained too. In [14] the properties of DPF as porous media are discussed and a four-port model for the filter was developed, all last models neglect the effects of the transverse velocity of exhaust gases and use the traditional design of the filter, while in [13] the traditional design is used, but the effects of transverse velocity of exhaust gases were taken into account and so a new 
model is developed which later called six-port model. In this paper a new design of DPF is developed, it still honey-comb, porous media and obeys six-port model assumptions.

Yang (2018) made another proposal to prolong the service life of DPF and create a novel waterbased recycling process. This water-based recycling process shows a higher recycling efficiency by discharging ash and debris several times, reducing the weight of the motor by half compared to the traditional calcination process. Moreover, this water-based recovery process can evacuate carbon residues, and can also remove most of the metal fragments implanted in the DPF channel. Hunsicker Emissions Service (HES)'s long-distance transportation perception provides good consistency between high and low ash accumulation DPF washing procedures.

Deng et al. ( 2019) talked about another diesel particulate channel (DPF) framework with responding stream is proposed, and a test concentrate on the attributes of the active-passive segment recovery of the DPF framework is completed. A few control parameters, for example, temperature dissemination, pressure distinction, and contamination discharges of the DPF framework are estimated for various responding cycles. The instrument of responding stream recovery of the DPF framework and the impacts of the responding stream cycle on the presentation of the DPF framework are dissected. Results indicated that (1) the DPF framework can utilize a small measure of additional fuel to keep up the compound response, which thusly understands the recovery of the catalysed DPF as a result of its properties of warmth recuperation and converse blowing of debris; (2) with the expansion in the responding stream cycle, the temperature profile pushes toward the downstream side of the DPF framework and the change amplitudes of the segments of $\mathrm{CO}, \mathrm{NO}$, and NO2 increment; (3) if sensible temperature dissemination is shaped in the DPF framework for a certain responding cycle, the recovery productivity can be clearly improved and the normal substance of particulate issue outflow can be kept at a significant low level.

\section{DPF Modelling}

\subsection{Geometry and Design: Inlet}

\section{section and porous media}

Inlet section is used to pass the exhaust gases coming from the engine through a steel pipe to the porous media, it is 1.5 meter long, 0.15 meter diameter. The inlet pipe is red highlighted in the figure below. The porous media is consisted of 10 disks each disk with 0.25 meter diameter and a thickness of 0.05 meter, so the length of the entire media is 0.5 meter. Permeability is a property of the porous medium that measures the capacity and ability of the formation to transmit fluids. Inertial resistance is the energy lost in the kinetic displacement of a fluid, usually represented by turbulence. Figure 4 shows the inlet section of the DPF. Table 2 shows the properties of the porous media of the DPF. This table shows three possible properties of porous media can be used in this study.

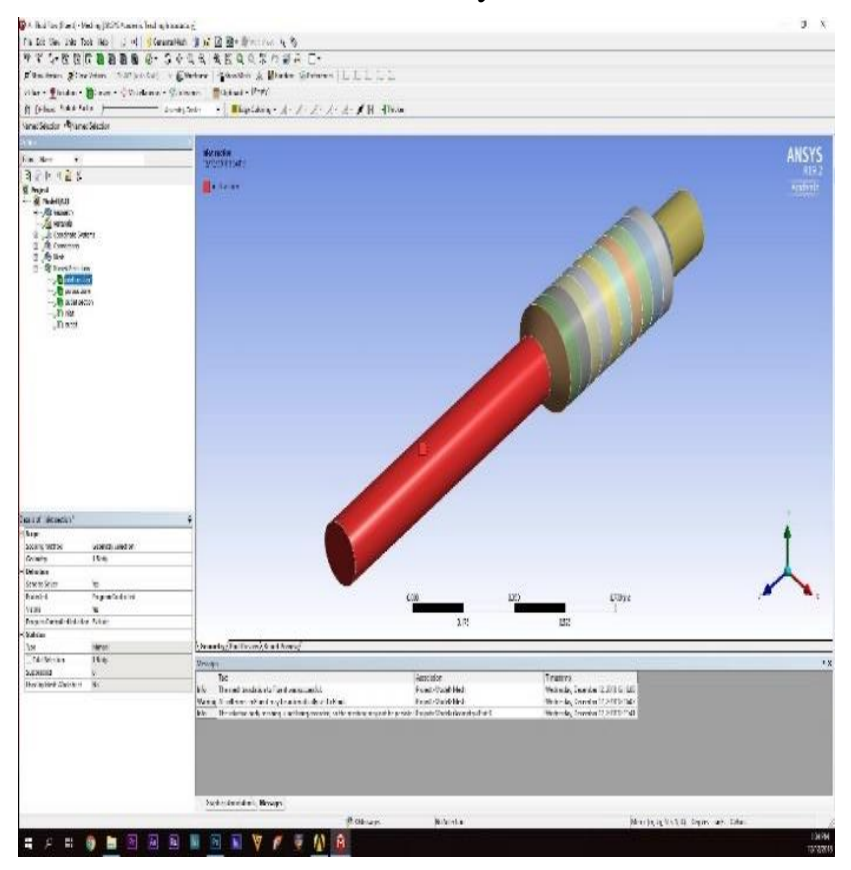

Fig 4: Inlet section 
Table 2: viscous and inertial resistance

\begin{tabular}{|l|l|l|}
\hline Direction & $\begin{array}{l}\text { Viscous } \\
\text { Resistance(inve } \\
\text { rse of } \\
\text { permeability) } \\
\left(1 / \mathrm{m}^{2}\right)\end{array}$ & $\begin{array}{l}\text { Inertial } \\
\text { Resistance } \\
(1 / \mathrm{m})\end{array}$ \\
\hline Direction-1 & $3.846 \mathrm{e}+07$ & 20.414 \\
\hline Direction-2 & $3.846 \mathrm{e}+10$ & 20.414 \\
\hline Direction-3 & $3.846 \mathrm{e}+10$ & 20.414 \\
\hline
\end{tabular}

In this model the aim of using 10 disks is to reduce the maintenance cost by making the disks replicable, the idea of this design is the ability to replace the blocked sections of the DPF with no need to replace the whole filter. While the Outlet is used to pass the exhaust gases from the porous media to the ambient, the pipe is made of steel and its diameter is 0.15 meter and 0.25 meter long. Figure 5 shows the outlet side of the DPF.

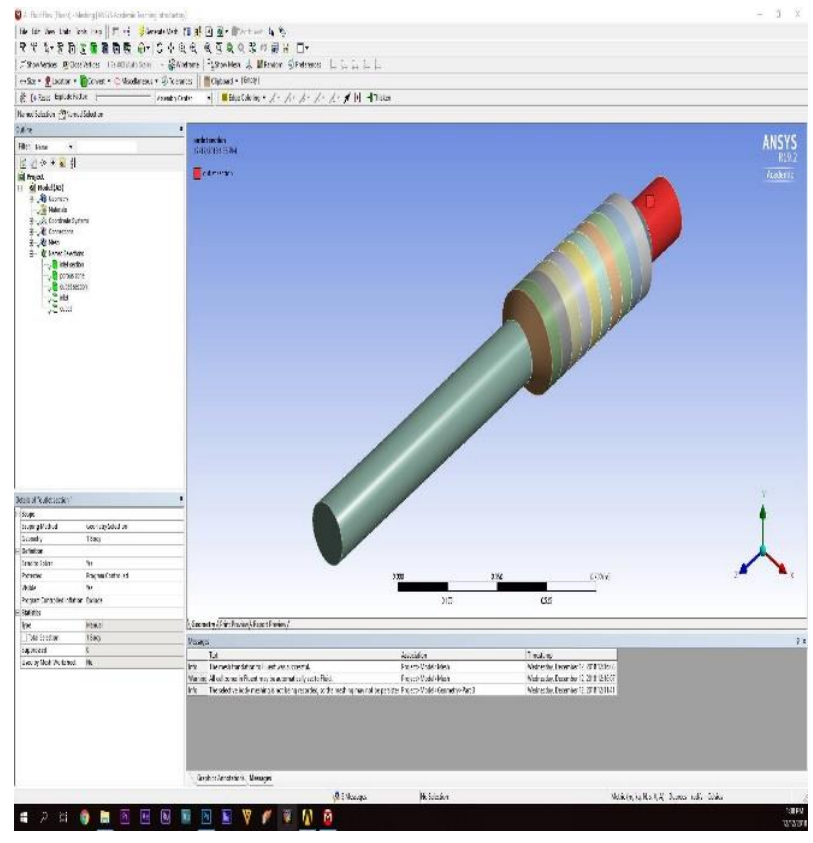

Fig 5: Outlet section

\section{- Meshing}

Meshing is defined as the process of dividing the entire component into a number of elements, so that each time the load is applied to the component, it distributes the load evenly called the mesh. The finer the mesh gives more accurate results, the model uses meshes by type of division, which has been divided into 50,000 divisions. Figure 6 shows a DPF mesh filter. Has a fine mesh property, which means the results are more accurate.

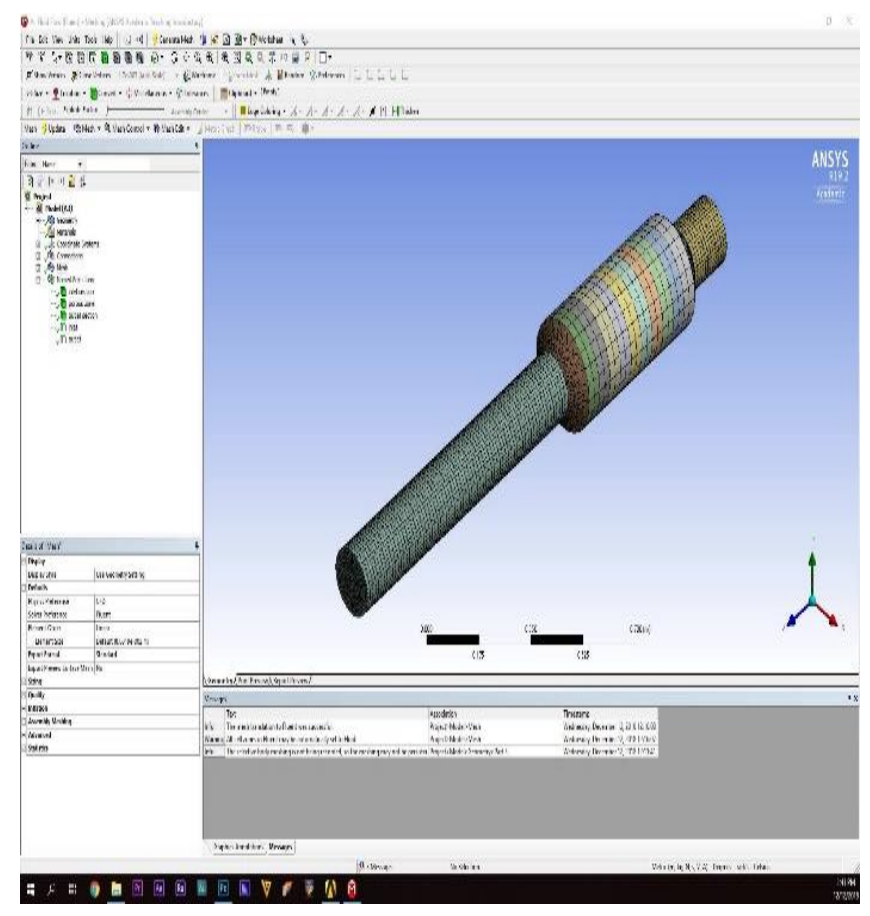

Fig 6: Meshing of DPF (50000 divisions)

\section{-materials and substances}

Steel was used in this model as a casing and as a material for the inlets and the outlet pipes. Because the exhaust gas mainly consist of nitrogen the flue gas was assumed to be nitrogen, this assumption will give a very good approximation of the pressure, velocity and temperature analysis. 


\section{-viscous model}

K-epsilon $(\mathrm{k}-\varepsilon)$ turbulence model is the most common model used in Computational Fluid Dynamics (CFD) to simulate mean flow characteristics for turbulent flow conditions. It is a two equation model that gives a general description of turbulence by means of two transport equations (PDEs). The original impetus for the K-epsilon model was to improve the mixing-length model, as well as to find an alternative to algebraically prescribing turbulent length scales in moderate to high complexity flows. Figure 7 shows the viscous model properties.

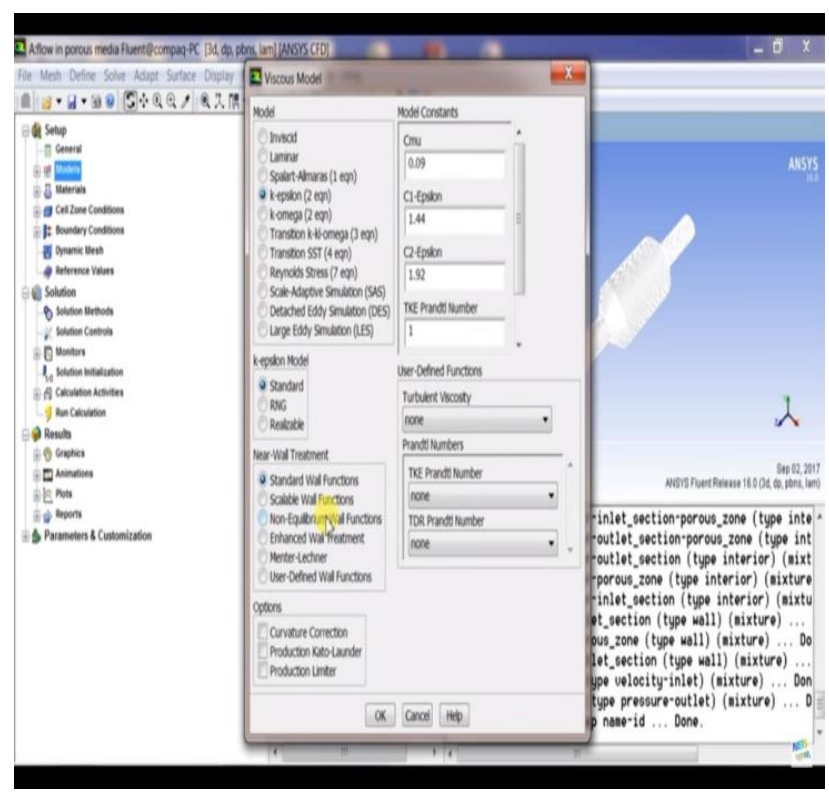

Fig 7: Choosing viscous model

Nitrogen was selected as the flowing gas in the DPF, the inlet and outlet was designed with no porosity, the flow in the porous zone is selected to be laminar flow in a porous media. Boundary conditions applied here are: inlet condition is velocity $22 \mathrm{~m} / \mathrm{s}$. outlet condition is pressure atmospheric pressure ( 0 gauge).

\section{Results and Discussion}

The calculation were running with 100 iteration includes mass flow rate of exhaust gases and their velocities of flow. Figure 8 and 9 show the boundary conditions and variations of these quantities with iteration.

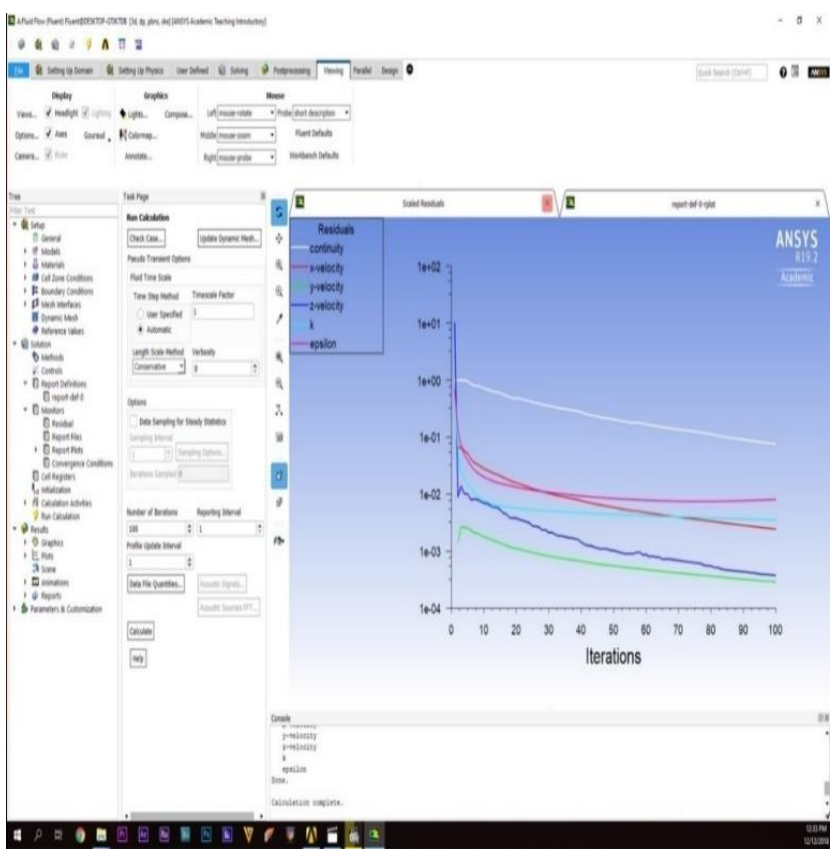

Fig 8: Velocities of flow and other variables with iterations. 

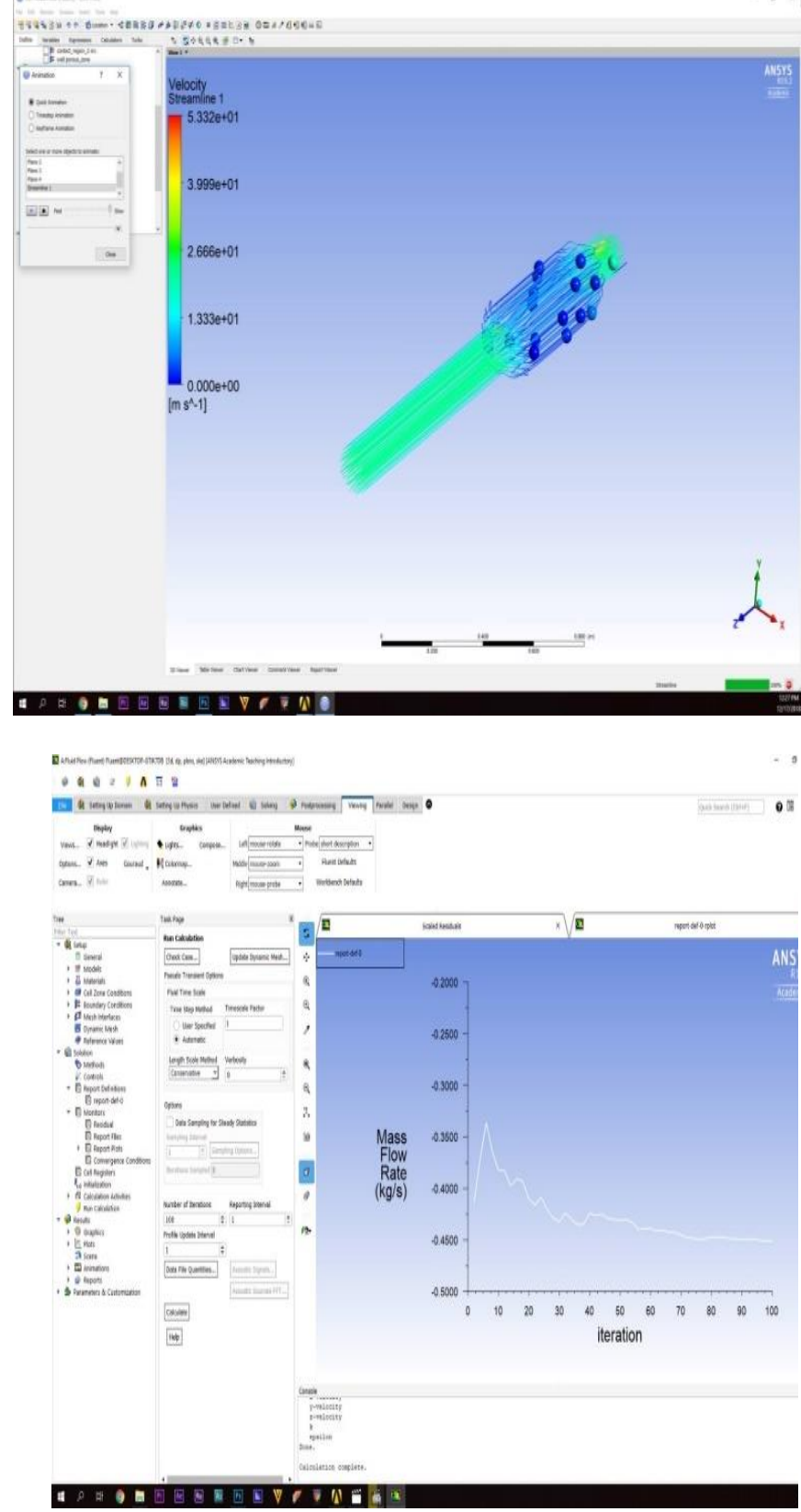

Fig 9: Mass flow rate variation with number of iterations

\section{-Velocity results and contours}

The inlet velocity was assumed to be $22.6 \mathrm{~m} / \mathrm{s}$, in this section the velocity stream lines, velocity contour and velocity vector results will be reviewed. In the two figures below we can see the velocity contours through the DPF, it is clear that a deceleration of the flue gases occur in the porous media, the reduction of speed is approximately around 3 . Speed reduction is an important factor of DPF because it cause a reduction in the noise level.

Figure 10 and 11 show velocity contours and distributions.

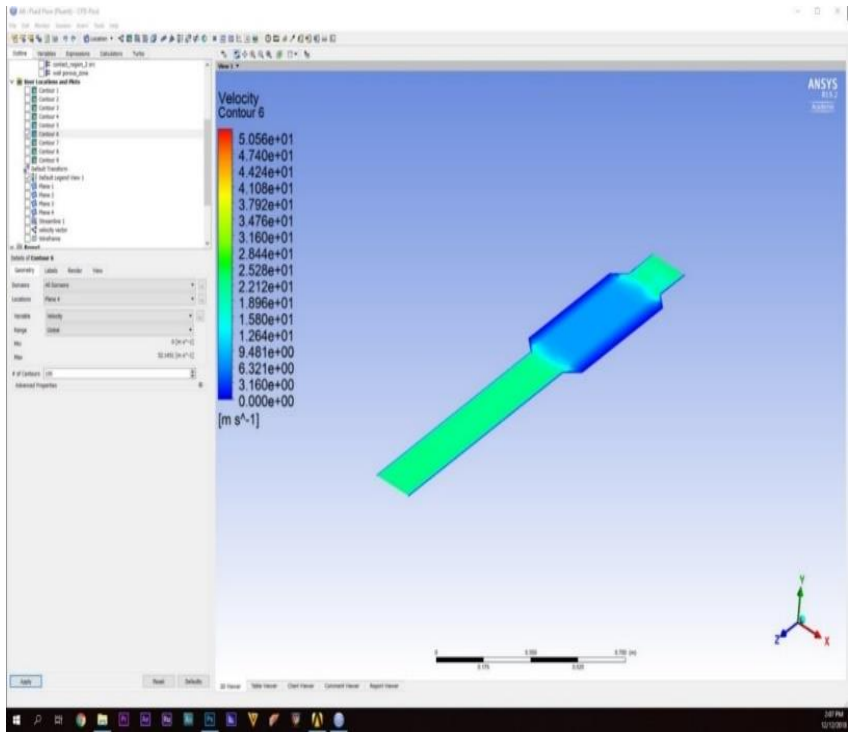

Fig 10: Velocity distribution through the whole model.

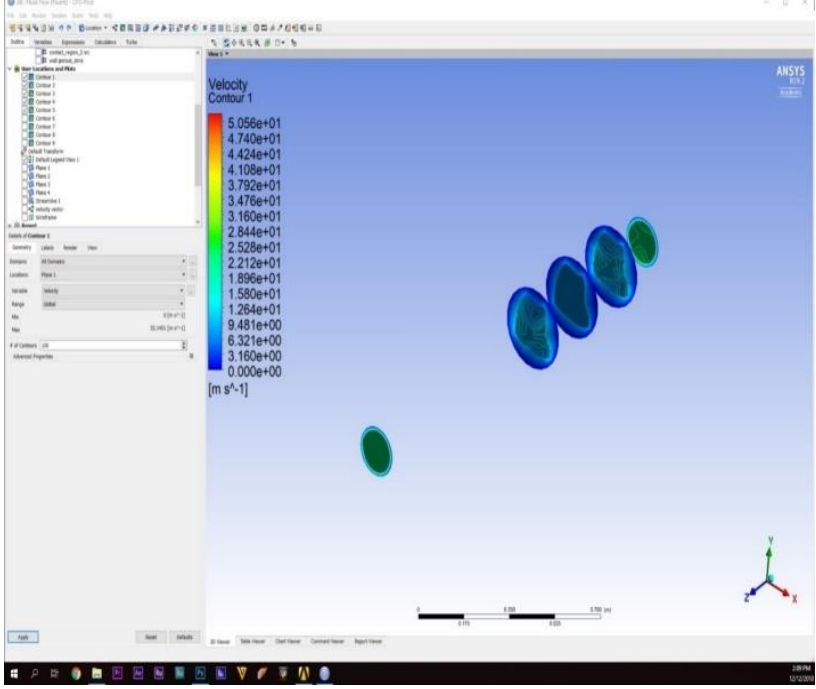

Fig 11: Velocity at different sections

Figure 12 shows the velocity stream lines of the flow gasses when passing the particulate filter and at different stages along the filter. 

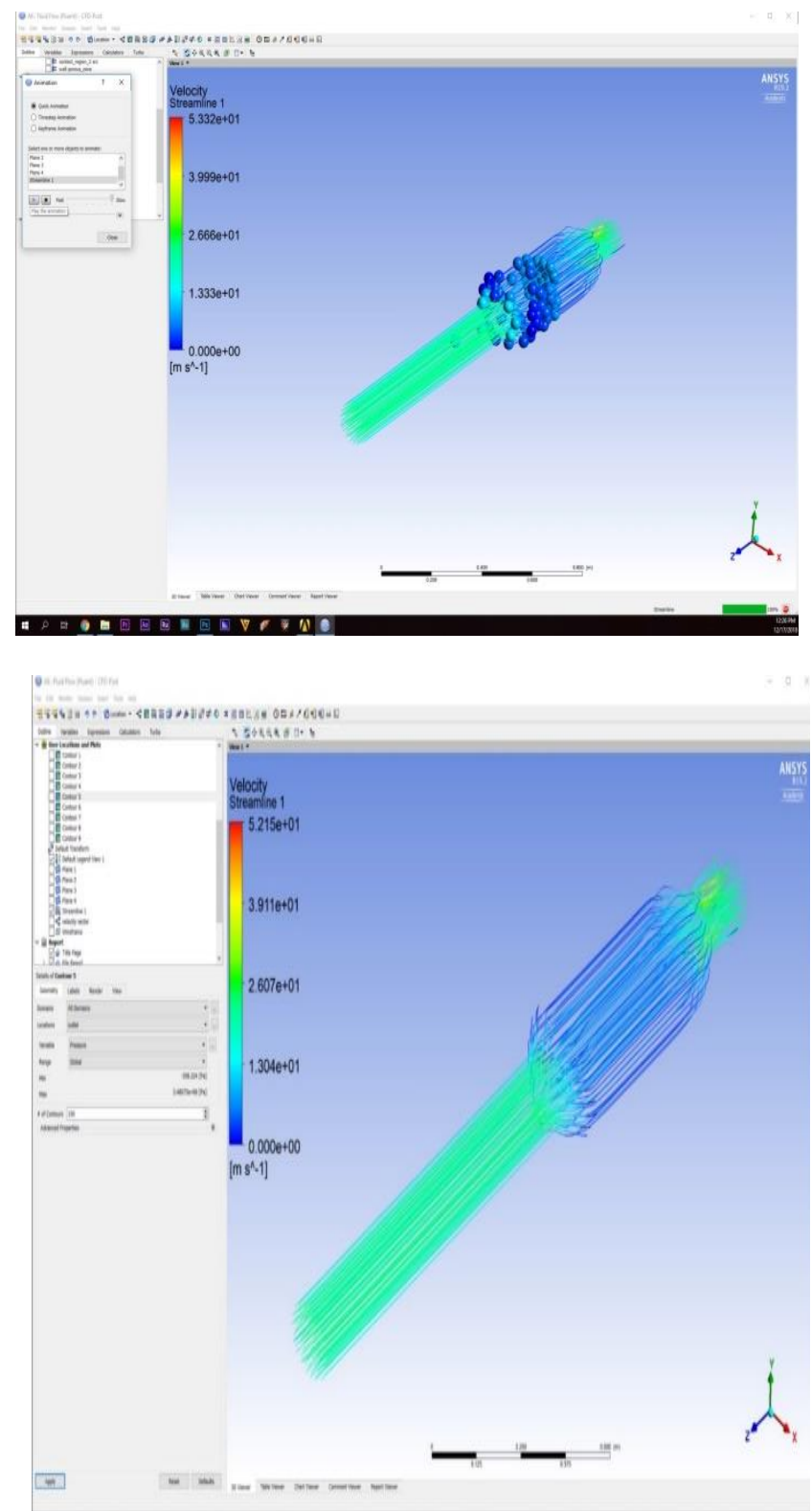

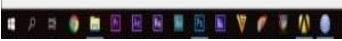

Fig 12: Streamlines at different stages along the DPF at inlet, at the nozzle, at the DPF porous media, and at the outlet

\section{-Pressure}

The pressure at the outlet was assumed as atmospheric. The pressure of the flow gas is reduced about 15 times after flowing through the porous media. The figures 13 and 14 below show the contours of the pressure at different sections and the pressure distribution through the whole model.

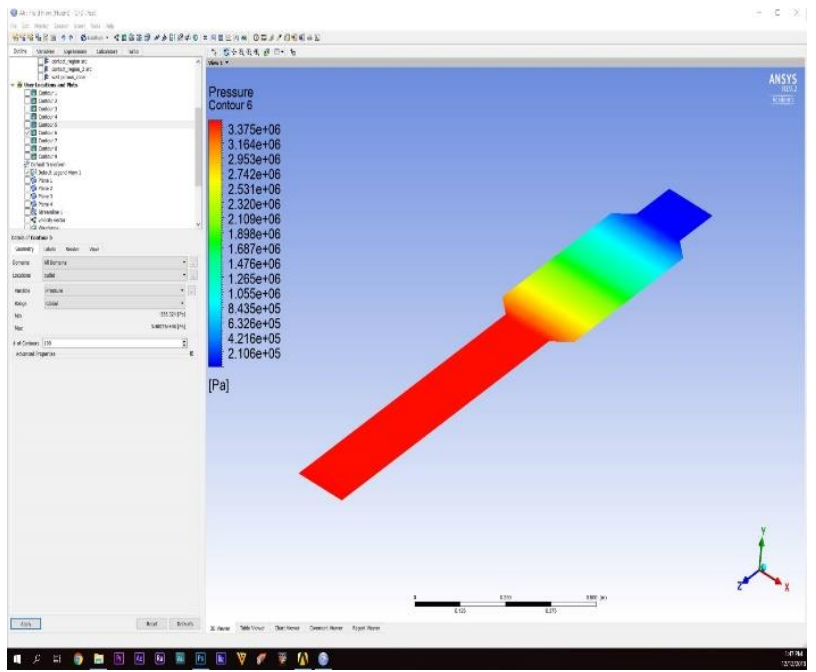

Fig 13: pressure distribution through the whole model.

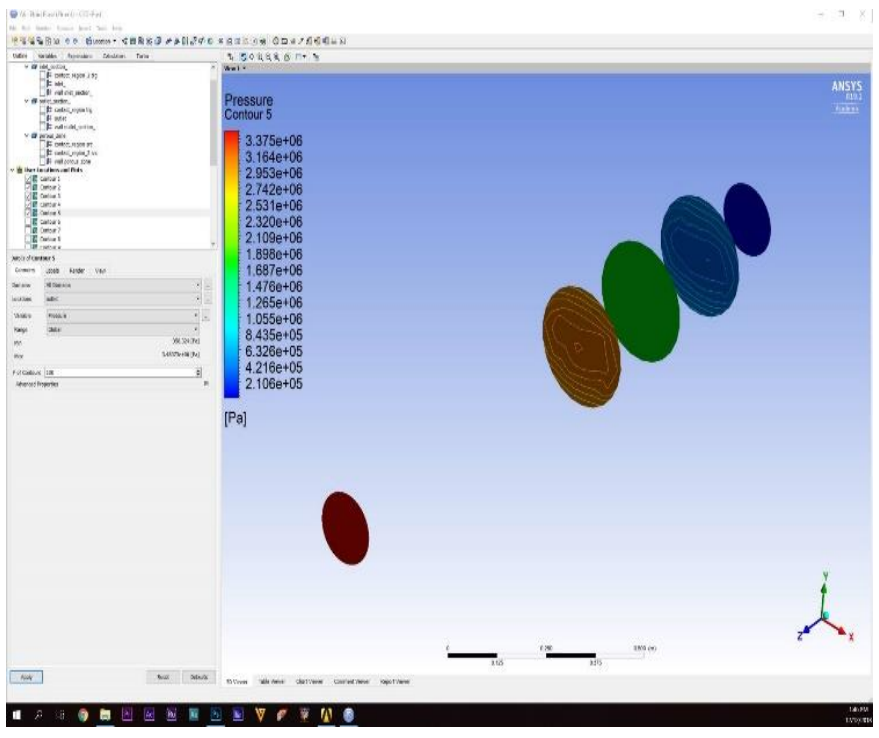

Fig 14: Pressure at different sections 
The high values of pressure difference between inlet and outlet indicates the high values of noise reduction occurred inside the DPF see Figure 15.

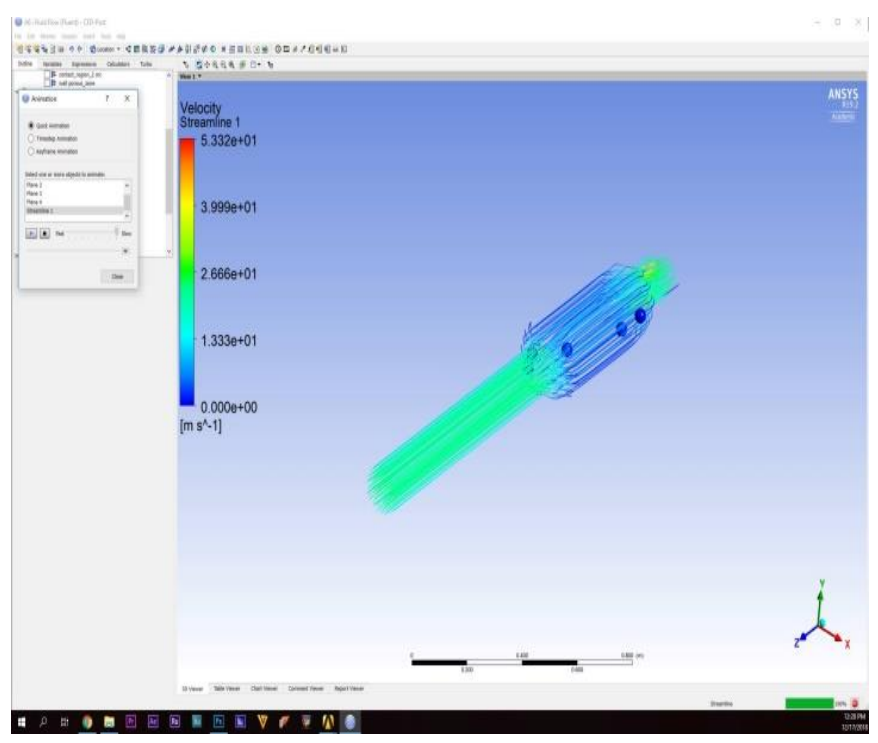

Figure 15: high values of pressure difference between inlet and outlet

\section{-Temperature}

The inlet gas temperature was determined 730 Kelvin. The figure bellow shows the thermal distribution through the model. It can be noticed from figure 16 that a higher temperature was appeared in the porous media, this happens due to the reduction of velocity. This temperature accumulation in the porous media necessary for the DPF to regenerate itself efficiently.

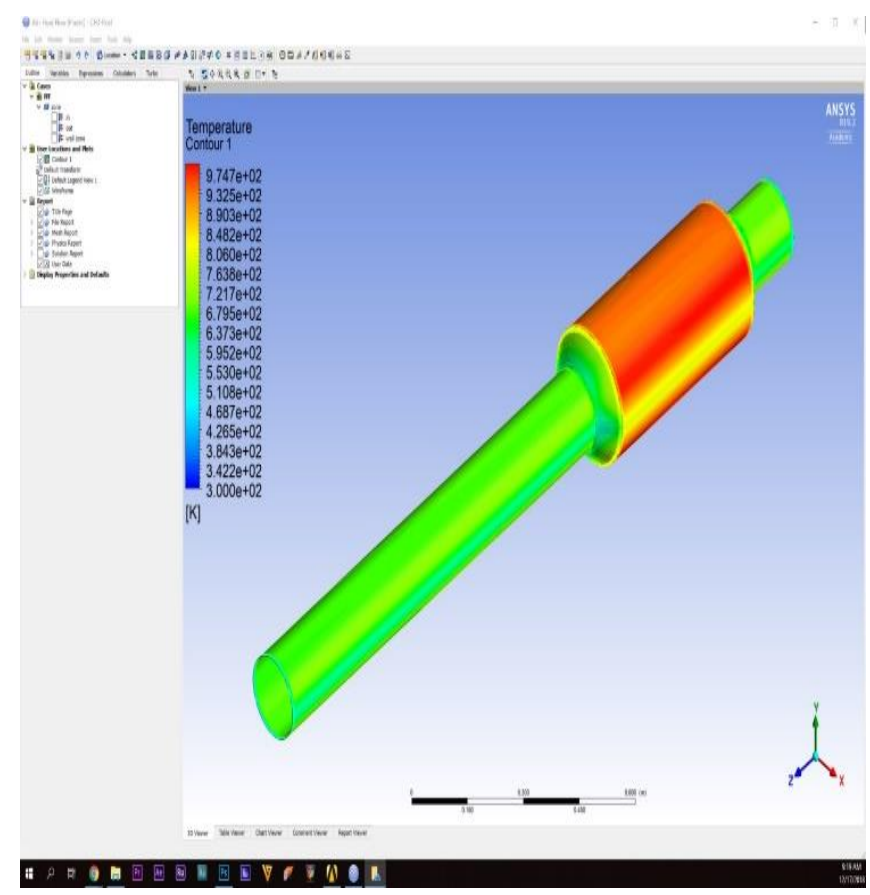

Fig 16: Thermal distribution through the model.

\section{-Noise Transmission Loss}

The transmission loss (TL) is expressed as the difference between the levels of the Arriving sound level and departing sound level

$\mathrm{TL}=-10 \ln (\mathrm{Wi} / \mathrm{Wt})$ 


\section{-Noise Reduction Coefficient}

\section{(NRC)}

NRC is the abbreviation for Noise Reduction Coefficient. In techno-speak it is the average of individual sound absorption coefficients by an element at 250, 500, 1000 and 2000 hertz. In a much simpler language, it is basically a measurement of how well something absorbs sound, mainly in the range of normal speech frequencies. NRC is a measure of how well the product makes the room quiet, NRC is usually between zero and 1.0.

$$
N R F=L P_{2}-L P_{1}=-20 \log \frac{P_{2}}{P_{1}}
$$

Or,

$$
N R F=T L+10 \log \frac{\alpha}{A}
$$

Where $\alpha$ : is the absorption coefficient, A is the cross-sectional area of the DPF and TL: is the transmission losses. For comparing transmission losses and noise reduction factor of the developed DPF and the last one developed by Fayyad and Hamdan (2006), it is assumed that they have the same cross sectional area A, and the same coefficient of absorption $\alpha$.

Figure 17 shows a comparison between the proposed DPF and that in the literature for the same assumptions and conditions.

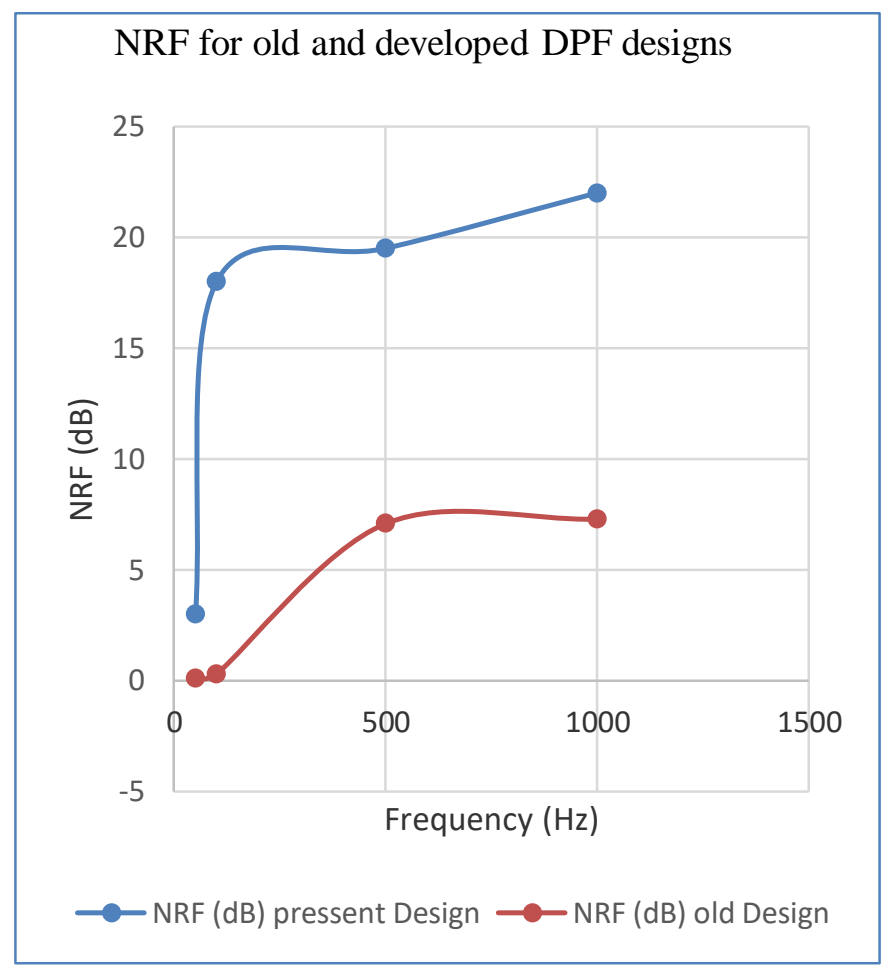

Fig 17: Noise reduction factor comparison

\section{Conclusion}

Ordinary DPF has a good performance in gas emissions and transmission losses or noise reduction, the four-port model developed by Allam et al. (2006) achieved a good progress in noise reduction, while the six-port model developed by Fayyad (2006) and other recent model has more performance than others. The present model is composed of successive porous media discs, which make more noise and gas reductions. As shown in results the developed design of DPF achieves about 22\% increase in its performance in both gas emission and noise reductions comparing with the traditional one. It is recommended to use different porous materials (it may be composite porous material) and compare their efficiency in noise reduction and gas emissions reduction. 


\section{References}

[1] M. Kermani (2015) Muffler design by noise transmission loss maximization, Master of Science in Mechanical Engineering thesis, Eastern Mediterranean University, North Cyprus.

[2] G. Greevesm, I. M. Khan, C. H. T. Wang, I. Fenne, "Origins of hydrocarbon emission from diesel engines". Society of Automotive Engineering, SAE Paper No. 770259, 1977, 0201.

[3] R. Yu, Yu, S. M. Shahed, "Effects of injection timing and exhaust gas recirculation on emissions from a DI diesel engine". Society of Automotive Engineering, SAE Paper No. 811234, 1981.

[4] G. Konstandopoulos, J. H. Johnson, "Wallflow diesel particulate filters - their pressure drop and collection efficiency", Society of Automotive Engineering, SAE Paper No. 890405, 1989.

[5] K. S. Peat, "A first approximation to the effects of mean flow on sound propagation in capillary tubes", Journal of Sound and Vibration Vol. 175, 1994, 475-489.

[6] R. J. Astley, A. Cummings, A., "Wave propagation in catalytic converter formulation of the problem and finite element scheme". Journal of Sound and vibration, Vol.188 , No. 5, 1995, 635-657.

[7] E. Dokumaci, "Sound transmission in narrow pipes with superimposed uniform mean flow and acoustic modelling of automobile catalytic converters", Journal of Sound and Vibration, Vol. $182,799-808,1995$.

[8] J.-G Ih, C. M. Park, H-J. Kim, ” A model for sound propagation in capillary ducts with mean flow". Journal of Sound and Vibration Vol. 190, No.2, 163-175, 1996.

[9] K.-W. Joeng, J.-G. Ih, (1996). “A numerical study on the propagation of sound through capillary tubes with mean flow", Journal of Sound and Vibration, Vol. 198, No. 1, 67-79, 1996.
[10] E. Dokumaci, "On transmission of sound in circular and rectangular narrow pipes with superimposed mean flow". Journal of sound and vibration, Vol. 210, No. 3, 1998, 375-389,1998.

[11] E. Dokumaci, "An approximate dispersion equation for sound waves in a narrow pipe with ambient gradients". Journal of Sound and Vibration, Vol. 240, No. 4, 2001, 637-646.

[12] S. Allam, S. M. Abom, "Acoustic modelling and testing of diesel particulate filters." Journal of Sound and Vibration, Vol. 288 (1/2), 255-273, 2005.

[13] S. Fayyad, "Sound propagation in porous media with application to diesel" particulate filters." PhD Thesis, University of Jordan, 2006. View publication

[14] S. Allam, S. M. Abom, "Sound propagation in an array of narrow porous channels with application to diesel particulate filters". Journal of Sound and Vibration, Vol. 291, 882-901, 2006.

[15] Yangbo Deng, Xiaolong Wang, Guangquan Chen, Hongwei Wu, Zhitao Han, and Rongrui Li (2019). Experimental Study on a Diesel Particulate Filter with Reciprocating. Flow. ACS Omega 2019, 4, 17098-17108.

[16] Kun Yang (2018). Understanding DPF failure, Improving DPF maintenance technologies, and advancing particulate filter materials. A Dissertation Presented to the Graduate and Research Committee of Lehigh University.

[17] Bond, T. C., Zarzycki, C., Flanner, M. G., and Koch, D. M. (2011). Quantifying Immediate Radiative Forcing by Black Carbon and Organic Matter with the Specific Forcing Pulse. Atmospheric Chemistry and Physics 11 (4): 1505-25. doi:10.5194/acp-11-1505-2011.

[18] Bond, T. C., Doherty, S. J., Fahey, D. W., Forster, P. M., Berntsen, T. K., DeAngelo, B. J., et al. (2013). Bounding the Role of Black Carbon in the Climate System: A Scientific Assessment. Journal of Geophysical Research-Atmospheres. doi:10.1002/jgrd.50171. 
[19] International Agency for Research on Cancer. (2012). IARC: Diesel Engine Exhaust Carcinogenic. Lyon, France: World Health Organization. Press Release, 12 June.

[20] Health Effects Institute (2010). TrafficRelated Air Pollution: A Critical Review of the Literature on Emissions, Exposure, and Health Effects. (HEI Special Report No. 17). Health Effects Institute, Boston, MA.

Contribution of individual authors

to the creation of a scientific article (ghostwriting policy)

Sayel m. Fayyad: constructing the model nad simulation requirements using ANSYS and CFD, also the article writing and discussion of results and final conclusions. The study is not funded.

\section{Creative Commons Attribution License 4.0 (Attribution 4.0 International, CC BY 4.0)}

This article is published under the terms of the Creative Commons Attribution License 4.0

https://creativecommons.org/licenses/by/4.0/deed.en_US 